\title{
Novel biosynthesis of monogalactosyl-alkylacyl glycerolipid in Mop8 fibroblast cells transfected with a ceramide galactosyltransferase gene
}

\author{
Ken-ichi Nagai ${ }^{1 *}$, Nobuyoshi Takahashi ${ }^{2}$ and Yukio Niimura ${ }^{3}$ \\ ${ }^{1}$ Department of Clinical Laboratory Science, Faculty of Medical Technology, Teikyo University, Japan \\ ${ }^{2}$ Department of Radiological Technology, Faculty of Medical Technology, Teikyo University, Japan \\ ${ }^{3}$ Department of Pathology, School of Medicine, Teikyo University, Japan
}

\begin{abstract}
Our recent study showed the activation of ceramide (Cer) glycosylation and Cer-related genes in the mouse fibroblast under heat stress. We investigated whether the Cer level was affected or not when the Cer galactosylation was introduced into a fibroblast cell line Mop8 by transfection of Cer galactosyltransferase (GalT, alternatively called UGT8) gene. When cells were labeled with ${ }^{14} \mathrm{C}$-galactose, the parental Mop8 cells showed only glucosylceramide (GlcCer) in the monohexosylceramide region on 2D-high-performance thin layer chromatography (HPTLC), whereas the transfectant cells (namely MopGT) expressed a spot corresponding to GalCer in addition to GlcCer. MopGT cells showed a significant decrease in intracellular Cer. These results suggest contribution of Cer glycosylation to the cellular regulation of Cer, which is known as a pro-apoptotic factor. Incidentally, another novel spot (which we referred to as GTX) moving more slowly than GalCer was observed in MopGT by the metabolic labeling. Comparison with the previous report that, in CHO cells transfected with the brain GalT gene, galactosyl-alkylacyl glycerol was stably expressed in addition to GalCer and was easily hydrolyzed with alkaline treatment to produce galactosyl-alkyl glycerol as the lyso form [van der Bijl $\mathrm{P}$ et al. (1996) Biochem J 317: 589-597] suggested that our GTX corresponded to galactosyl-alkyl glycerol. Indeed, when GTX prepared by the HPTLC was analyzed by mass spectrometry (MS), m/z 501, 527 and 529 were predominantly observed as $[\mathrm{M}+\mathrm{Na}]^{+}$, which were consistent with monogalactosyl-monoalkyl glycerol containing an alkyl chain of 16:0, 18:1 and 18:0, respectively. Galactosyl-alkylacyl glycerol (namely, GTXorg) was also prepared by preparative TLC without alkaline treatment. MS spectrum of GTXorg showed molecular ions corresponding to 16:0 alkyl and 16:0 acyl chains, 18:1 alkyl and 16:0 acyl chains, and 18:0 alkyl and 16:0 acyl chains, respectively. These findings support the view that substrate recognition of the ceramide-binding site of GalT is not very specific, accepting glycerolipids as substrates.
\end{abstract}

\section{Introduction}

Cer is a major bioactive lipid in eukaryotic cells and plays the role of a lipid second messenger in cell signaling transductions $[1,2]$. Cer is believed to be involved in a variety of cellular functions including the regulation of cell growth, differentiation, and viability. Furthermore, many anti-cancer drugs are able to induce endogenous ceramide production to promote cancer cell apoptosis [3]. It is well known that various stresses such as high temperature and ultraviolet irradiation elevate intracellular Cer levels followed by cell apoptosis [4]. In previous studies we demonstrated that hyperosmotic stress to MDCK cells increased Cer content, and the mRNA level of GalT was upregulated resulting in GalCer accumulation [5]. Hyperosmotic stress also affected the syntheses of more complex glycosphingolipids such as sulfoglycolipids by the MAPK signaling pathway [6]. In our recent study heat-stressed MDCK cells had an increased content of Cer, and the de novo synthesis from serine and both GlcCer and GalCer syntheses from Cer were shown to increase by metabolic labeling [7]. The gene expression of Cer glucosyltransferase (GlcT) and GalT also increased significantly under heat stress. Thus, we speculated that accumulation of Cer under heat stress might be a trigger to activate the synthesis of monohexosylceramides (GlcCer and/or GalCer) to decrease the intracellular Cer level and evade cell apoptosis. We confirmed that the increment of Cer and its subsequent glycosylation also occurred in Mop8 (polyomavirus-transformed mouse fibroblast) cells under heat stress [8]. In the present study, we investigated whether the Cer level was affected or not when the Cer galactosylation was introduced into Mop8 by transducing GalT gene. In the transfectant, which we referred to as MopGT, novel galactosyl glycerolipid was stably expressed in addition to GalCer in accordance with the previous study with $\mathrm{CHO}$ cells [9], and this lipid was easily hydrolyzed with alkaline treatment to produce galactosyl-alkyl glycerol as the lyso form. The Cer metabolism in this transfectant, molecular species of the newly expressed glycosyl glycerolipid characterized with matrix-assisted laser desorption ionization time of flight mass spectrometry (MALDI-TOF MS) with high energy collision-induced dissociation (CID) are discussed.

\section{Materials and methods}

\section{Reagents and standards}

GlcCer and lactosylceramide (LacCer) were prepared in our

Correspondence to: Ken-ichi Nagai, Department of Clinical Laboratory Science, Faculty of Medical Technology, Teikyo University, 2-11-1 Kaga Itabashi-ku, Tokyo, Japan, Tel: 03-3964-1211, E-mail: knagai@med.teikyo-u.ac.jp

Key words: ceramide (Cer); galactosyl-alkylacyl glycerol; galactosylceramide (GalCer); galactosyltransferase (GalT) gene; collision-induced dissociation (CID); matrix-assisted laser desorption ionization time of flight mass spectrometry (MALDI-TOF MS)

Received: May 26, 2016; Accepted: July 29, 2016; Published: July 31, 2016 
laboratory from horse and human kidney, respectively. GalCer from bovine brain, phosphatidylserine (PS), phosphatidylcholine (PC), phosphatidylethanolamine (PE) and sphingomyelin (SM) were obtained from Sigma-Aldrich Co. (St. Louis, MO, USA). Cer from bovine brain was purchased from Funakoshi Co. (Tokyo, Japan). Protein concentrations were determined with Quick Start Bradford Dye Reagent (Bio-Rad, Hercules, CA, USA). Thin layer chromatography (TLC) was performed on Silica gel 60 high-performance TLC (HPTLC) plates (Merck, Darmstadt, Germany). Orcinol reagent was used for detection of glycolipids and primuline reagent was used for detection of lipids.

\section{Cell culture}

Mop8 cells [10] with a hybrid transcription unit composed of the SV40 early promoter fused to the early region of Polyoma virus were purchased from American Type Culture Collection and cultured in Dulbecco's modified Eagle's medium (Nissui Pharmaceutical Co., Tokyo, Japan) containing $10 \%$ fetal bovine serum (Invitrogen, Carlsbad, CA, USA).

\section{Construction of plasmid pSV-GT-E22 and transfection}

Rat brain GalT gene [11] was cloned by one step RNA PCR kit (Takara Bio, Ohtsu, Shiga, Japan) using rat brain mRNA as a template and a primer set (5'-ggacgcgctatgaagtcttata- $3^{\prime}$ and 5'-tcaatgaccgacacatatctgc-3'). The PCR amplicon (1679 bp) was ligated with the vector (pSV2neo) to construct pSV-GT-E22, which was transfected to Mop8 cell and the neomycin-resistant MopGT cells were selected. This transformant cell expressed GalCer permanently.

\section{Metabolic labeling of cer and glycolipids}

${ }^{14} \mathrm{C}(\mathrm{U})$-1-serine $(24.7 \mathrm{kBq} / \mathrm{mL}$; Moravek Biochemicals Inc., Brea, CA, USA) was incorporated into Cer for $16 \mathrm{~h}$ under various conditions. Lipids were extracted and then partitioned with a Folch solvent system containing $0.88 \%$ potassium chloride. An aliquot of the lower phase was analyzed by HPTLC using stepwise development with two solvents: the first was with chloroform/methanol/acetic acid (9:1:1, v/v) up to the top of the plate, and the second was with chloroform/methanol/ ammonia $(65: 35: 7.5, \mathrm{v} / \mathrm{v})$ up to $60 \%$ of the top of the plate. Following TLC, an imaging analyzer (FLA-7000, Fujifilm, Tokyo, Japan) was used to determine radioactivity incorporated into the lipids. Cer, PE, PS, PC, and SM used as standards for TLC were detected by spraying the primuline reagent. Labeling with $\left[1-{ }^{14} \mathrm{C}\right]$-d-galactose (Moravek Biochemicals Inc.) was performed under the directed conditions. Cells were cultured for $5 \mathrm{~h}$ with ${ }^{14} \mathrm{C}$-galactose $(37 \mathrm{kBq} / \mathrm{mL})$, after which lipids were extracted twice with chloroform/methanol (2:1 and 1:2, v/v). Cell lipids were then treated with alkaline methanol. After neutralization and desalting, the neutral glycolipid fraction was obtained using a DEAE- Sephadex ${ }^{\oplus}$ A-25 (Pharmacia Fine Chemicals AB, Uppsala, Sweden) column. Neutral glycolipids were two-dimensionally developed on HPTLC plates using chloroform/methanol/water (60:25:4, v/v) and 2-propanol/ammonium hydroxide/methyl acetate/ water (15:2:1:3, v/v) [5-7]. Total radioactivity incorporated into the glycolipids was measured using a liquid scintillation counter (Packard Instrument Co. Inc., Downers Grove, IL, USA). In the case without alkaline treatment, cells were cultured for $24 \mathrm{~h}$ with $\left[1-{ }^{14} \mathrm{C}\right]$-d-galactose $(7.4 \mathrm{kBq} / \mathrm{mL})$. After cell lipids were extracted as above, the crude extract was partially purified by partitioning. GTXorg was isolated by TLC using chloroform/methanol/water (60:25:4, v/v). After alkaline treatment of GTXorg, GTX was also prepared by TLC.

\section{Preparation of glycolipids and TLC analysis}

Non-radioactive glycolipids were also prepared from cells by chloroform/methanol extraction, mild alkaline treatment, DEAESephadex ${ }^{\oplus}$ A-25 column chromatography, and TLC as mentioned above. The glycolipids on TLC were visualized by spraying the plate with orcinol- $\mathrm{H}_{2} \mathrm{SO}_{4}$ reagent and heating for several minutes at $120^{\circ} \mathrm{C}$.

\section{Mass spectrometric analysis}

MALDI-TOF MS for lipid samples was carried out on an AXIMA Performance mass spectrometer (Shimadzu Biotech, Manchester, UK) using 2,5-dihidroxy benzoic acid (DHB, Bruker Daltonics, Bremen, Germany) saturated with sodium chloride as a matrix [12]. Angiotensin II (Shimadzu GLC Ltd.; $\mathrm{M}+\mathrm{H}^{+}$of m/z 1046.54), C16 Cer (Funakoshi; $\mathrm{M}+\mathrm{H}^{+}$of $\mathrm{m} / \mathrm{z}$ 537.90) and $\alpha$-cyano-4-hydroxycinnamic acid (Shimadzu GLC Ltd.; $\mathrm{M}+\mathrm{H}^{+}$of $\mathrm{m} / \mathrm{z}$ 190.05) were used for mass calibration. Lipid solution $(0.5 \mu \mathrm{L})$ was mixed with a matrix solution $(0.5 \mu \mathrm{L})$ on the surface of a stainless steel MALDI-TOF plate. All spectra were acquired in the positive ion reflectron mode using a mass spectrometer equipped with a nitrogen UV laser $(337 \mathrm{~nm})$. All mass spectrometric data were acquired and analyzed using MALDIMS software. Typically, 4000 laser shots were acquired for each MS spectrum, and spectra were obtained generally at a laser power of 80 in an attempt to maximize resolution and peak intensity, and analyzed using MALDI-MS software. Helium gas was used for high-energy CID fragmentation for MS/MS analysis.

\section{Statistical analysis}

Statistical significance was evaluated using unpaired $t$ test; $\mathrm{P}<0.05$ was considered statistically significant.

\section{Results}

\section{Synthesis of new glycolipids in Mop8 cells transfected with GalT gene}

Rat brain GalT gene was cloned by PCR and was constructed to plasmid vector pSV2neo to produce a new pSV-GT-E22 vector. Mop8 cells were transfected with this vector and the neomycin resistant transformant cells, namely MopGT, were selected. Glycolipids were prepared from both Mop8 and MopGT cells by chloroform/methanol extraction followed by mild alkaline treatment, DEAE-Sephadex ${ }^{\oplus}$ A-25 column chromatography and TLC. Glycolipids of Mop8 cells and MopGT cells were metabolically labeled with ${ }^{14} \mathrm{C}$-galactose for $5 \mathrm{~h}$. The neutral glycolipids were separated by 2D-HPTLC analysis using a two-solvent system. The plates were analyzed by an imaging analyzer (Figure 1). Figures 1A and 1B show the glycolipid profiles of Mop8 cells and MopGT cells, respectively. GlcCer and LacCer of Mop8 cells comigrated with their authentic references. Incorporation of ${ }^{14} \mathrm{C}$-galactose into both GlcCer and LacCer was unchanged by the transfection of GalT gene (Figures 1C and 1D). The slower moving spots (designated as GalCer) than GlcCer co-migrated with the authentic GalCer (Figure 1B). In this plate another novel spot (designated as GTX) was detected as a faster moving spot than authentic LacCer (Figure 1B). These two novel lipids were identified as glycolipids based on the orcinol positive reaction on HPTLC (data not shown).

\section{Cer and phospholipid metabolism in MopGT cells}

Cer and phospholipids extracted from cells were analyzed by HPTLC using a two-step development process with two solvent systems. MopGT cells significantly reduced the incorporation of 
A

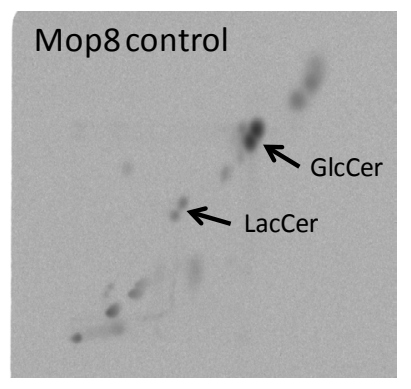

C

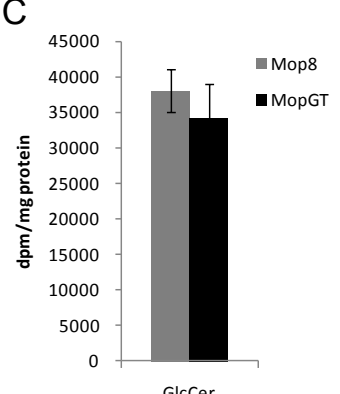

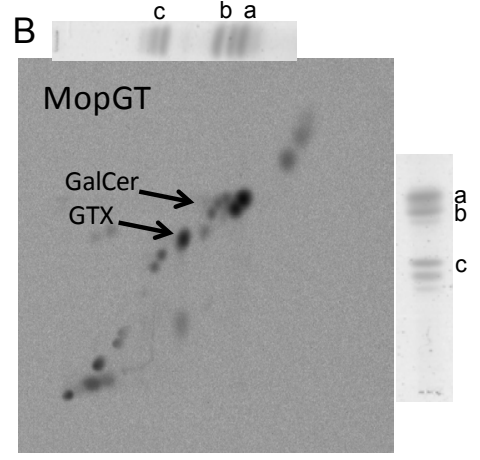

D

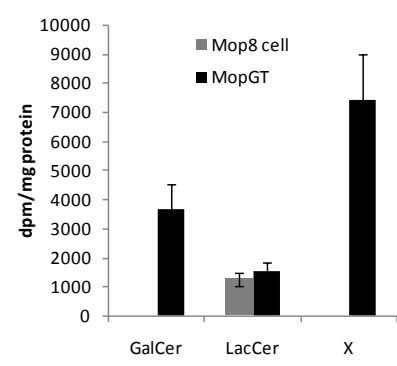

Figure 1. Synthesis of new glycolipids in MopGT cell. Confluent cells were cultured at $37^{\circ} \mathrm{C}$ for $15 \mathrm{~h}$. Cells were then labeled with ${ }^{14} \mathrm{C}$-galactose $(37 \mathrm{kBq} / \mathrm{mL})$ at $37^{\circ} \mathrm{C}$ for $5 \mathrm{~h}$. Neutral glycolipids were prepared as described in the Materials and Methods section and developed by 2D-HPTLC with chloroform/methanol/water $(60: 25: 4, \mathrm{v} / \mathrm{v})$ in the vertical direction and 2-propanol/ammonium hydroxide/methyl acetate /water (15:2:1:3, v/v) in the horizontal direction. The ${ }^{14} \mathrm{C}$-incorporation into neutral glycolipids was analyzed with the radio imaging. Reference glycolipids were visualized with spraying the orcinol reagent. (A) Mop8 cell in control culture, (B) MopGT cell, a; GlcCer (horse kidney), b; GalCer (bovine brain), c; LacCer (human kidney), (C) incorporation into GlcCer, (D) incorporation into GalCer, LacCer and X (GTX).

${ }^{14} \mathrm{C}$-serine into Cer by $42 \%$ compared to Mop8 cells, the incorporation into PC also significantly decreased by $33 \%$ (Figure $2 \mathrm{~B}$ ). Cer content determined by spraying primuline reagent showed $29 \%$ reduction in MopGT cells (Figures 2C and 2D). These results demonstrated that galactosylation of Cer decreased the cellular Cer content without any changes in GlcCer and LacCer, arguing a role for GalT in the control of Cer concentration. SM that is synthesized from Cer by sphingomyelin synthase also did not decrease significantly.

\section{Analysis of GTX and GTXorg in MopGT cells by MALDI- TOF MS}

After cells were labeled with ${ }^{14} \mathrm{C}$-galactose, lipids were extracted from Mop8 and MopGT cells and were compared with or without alkaline treatment on HPTLC (Figure 3). In MopGT cells the faster moving spot (named GTXorg) than GlcCer was detected in the extract without alkaline treatment (lane 2), and the slower moving spot (GTX) than GalCer was detected in the extract with alkaline treatment (lane 4). When GTXorg spot (lane 2) was isolated from HPTLC and was treated with alkali, the product (lane 6) comigrated with GTX spot (lane 4) on HPTLC. Thereafter, GTX and GTXorg were purified from non-labeled cell extract with or without alkaline treatment by preparative HPTLC for MALDI-TOF MS analyses.

GTX was analyzed by MALDI-TOF MS (Figure 4). Its spectrum showed three ion peaks at $\mathrm{m} / \mathrm{z} 501.19,527.27$, and 529.31. Peaks at $\mathrm{m} / \mathrm{z}$ 501,527 and 529 correspond to sodiated molecular ions $\left([\mathrm{M}+\mathrm{Na}]^{+}\right)$of monohexosyl-monoalkyl glycerol containing alkyl chain of 16:0, 18:1 and 18:0, respectively (Figure $4 \mathrm{~A}$ ). MS/MS analysis of $\mathrm{m} / \mathrm{z} 501$ with

high-energy CID fragmentation showed typical fragments ions derived from a part of hexose (Hex) (m/z 113 and 157), a Hex (m/z 185 and 201) and a part of hexosyl glycerol (m/z 243) (Figures $4 \mathrm{~B}$ and $4 \mathrm{C}$ ). Ion cluster (m/z 317, 331, 345, 359, 373, 387, 401, 415, 429, 443, 457, 471 and 485$)$ with a difference of $14 \mathrm{Da}\left(-\mathrm{CH}_{2}-\right)$ were observed, indicating the ions derived from alkyl chain of C16:0. Other fragment ions were also assigned as in Figure 4C. We also analyzed the molecular ion of $\mathrm{m} / \mathrm{z}$ 529 with CID fragmentation to reveal the structure of monohexosylmonoalkyl glycerol containing C18:0 (Figure 4D). Molecular ion of $\mathrm{m} / \mathrm{z} 527$ corresponding to $\mathrm{C} 18: 1$ as a minor peak was not analyzed with CID fragmentation.

GTXorg spectrum showed three molecular ions $\mathrm{m} / \mathrm{z} 739.35$, 765.36 and 767.37, which correspond to combinations of C16:0 alkyl and C16:0 acyl chains, C18:1 alkyl and C16:0 acyl chains, and C18:0 alkyl and C16:0 acyl chains, respectively (Figure 5A). Peak at m/z 739 corresponds to a sodiated molecular ion of monohexosyl-monoalkylmonoacyl glycerol containing an alkyl chain of C16:0 and an acyl chain of C16:0. MS/MS analysis of $\mathrm{m} / \mathrm{z} 739$ with high-energy CID fragmentation showed typical fragment ions derived from a part of Hex (m/z 113 and 157), a Hex (m/z 185 and 203) and a part of hexosyl glycerol $(\mathrm{m} / \mathrm{z} 243)$ (Figures $5 \mathrm{~B}$ and $5 \mathrm{C}$ ), as observed in GTX (Figures $4 \mathrm{~B}$ and $4 \mathrm{C})$. A predominant ion $(\mathrm{m} / \mathrm{z} 483)$ might derive from GTXorg without acyl chain (Figures $5 \mathrm{~B}$ and $5 \mathrm{C}$ ). This ion $(\mathrm{m} / \mathrm{z} 483$ ) could be also observed in GTX spectrum (Figure 4B) as $\left[\mathrm{M}-\mathrm{H}_{2} \mathrm{O}-\mathrm{Na}\right]^{+}$. Conversely, GTXorg without alkyl chain generated a minor ion (m/z 499) (Figure

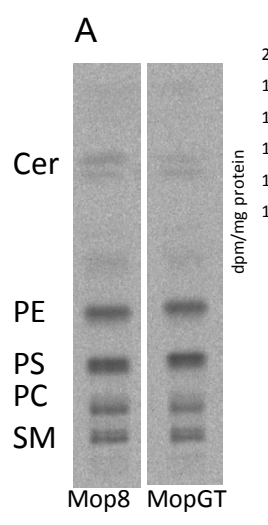

C

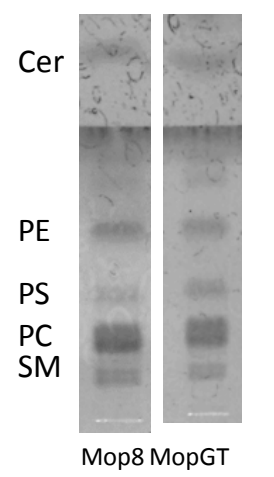

B

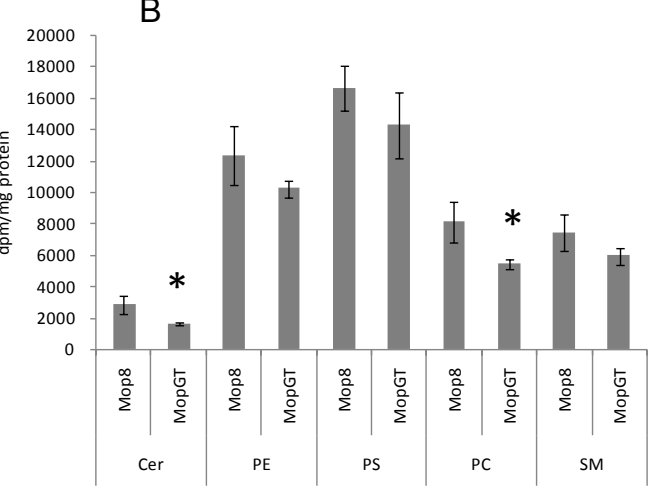

D

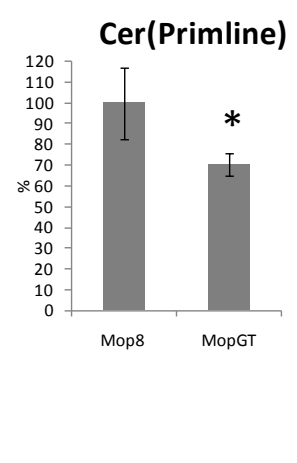

Figure 2. Changes of Cer and phospholipids metabolism in MopGT cells.Confluent cells were cultured with ${ }^{14} \mathrm{C}$-serine $(37 \mathrm{kBq} / \mathrm{mL})$ at $37^{\circ} \mathrm{C}$ for $16 \mathrm{~h}$. Total lipids prepared as described in the Materials and Methods section were separated by HPTLC with chloroform/ methanol/acetic acid $(9: 1: 1, \mathrm{v} / \mathrm{v})$ in the first run, the plate was dried and then re-developed with chloroform/methanol/acetic acid/water $(25: 15: 4: 2, \mathrm{v} / \mathrm{v})$ until $65 \%$ of the solvent top of the first run. (A) Representative TLC imaging patterns of lipids, (B) ${ }^{14} \mathrm{C}$-incorporation into lipids, (C) Representative TLC imaging patterns of lipids detected by primuline reagent (D) Cer content determined by primuline reagent. *Significant difference, $\mathrm{P}<0.05(\mathrm{n}=4)$. 


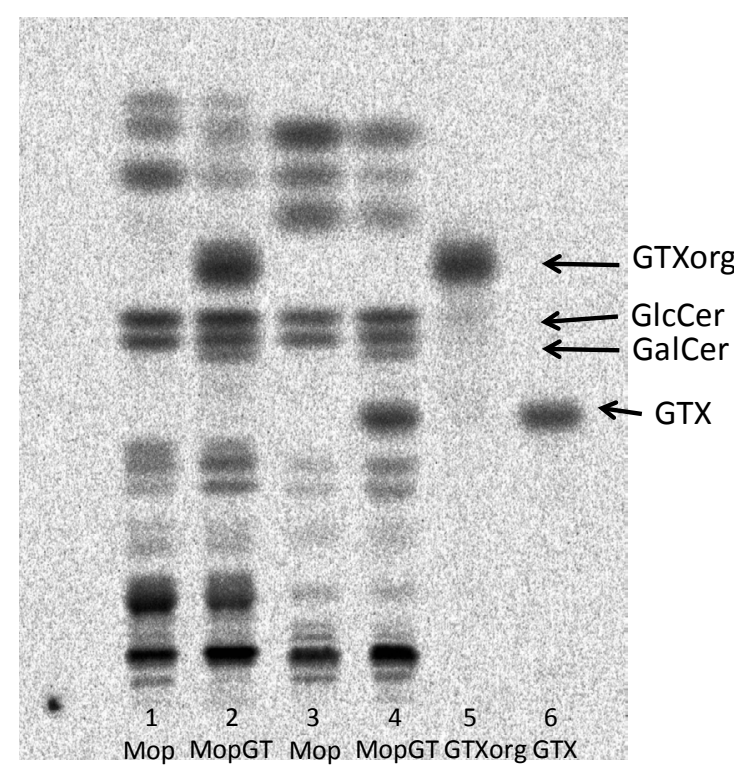

Alkaline treatment -

Figure 3. Preparation of GTX and GTXorg.TLC-radioimaging of lipid extract from cells. Labeled lipids were developed with the solvent of chloroform/methanol/water (60:25:4). Lane 1, total lipid extract from Mop8 cells without alkaline treatment.

Lane 2, total lipid extract from MopGT cells without alkaline treatment.

Lane 3, total lipid extract from Mop8 cells with alkaline treatment.

Lane 4, total lipid extract from MopGT cells with alkaline treatment.

Lane 5, GTXorg prepared from TLC plate.

Lane 6, product of GTXorg after alkaline treatment.

$5 \mathrm{~B}$ and $5 \mathrm{C}$ ). The same cleavage between $\mathrm{C}-1$ of glycerol and alkyl chain of GTX showed an ion at $\mathrm{m} / \mathrm{z} 259$ (Figure $4 \mathrm{~B}$ and $4 \mathrm{C}$ ). Ion cluster $(\mathrm{m} / \mathrm{z}$ $555,569,583,597,611,625,639,653,667,681,695,709$ and 723 ) with a difference of $14 \mathrm{Da}\left(-\mathrm{CH}_{2}{ }^{-}\right)$were observed, indicating that the ions leave methylene group successively from the alkyl or acyl chain of C16:0 (Figure 5B). Simultaneous analysis of $\mathrm{m} / \mathrm{z}$ 765-767 molecular ion region with CID fragmentation revealed the structure of monohexosylmonoalkyl-monoacyl glycerol containing an alkyl chain of C18:1 or C18:0 and an acyl chain of C16:0 (Figure 5D). Because alkyl chains of C18:1 and C18:0 have been detected from the analysis of GTX (Figure 4), the possibility that GTXorg has an alkyl chain of C16:0 and an acyl chain of C18:1 or C18:0 was excluded.

\section{Discussion}

In our previous study, we confirmed that the expression of the GlcT gene in Mop8 fibroblasts was activated in a temperature-dependent manner under heat stress [8]. This activation of GlcT gene induced an increase of GlcCer, resulting in a decrease in intracellular Cer. Komori et al. [13] reported that GlcT functions to regulate the level of intracellular Cer of B16 melanoma cells by glycosylation of the Cer when it is present in excess. Uchida et al. [14] also reported that upregulation of GlcCer synthesis in keratinocytes may protect against the deleterious effects of excess Cer. In the present study when the Cer galactosylation was introduced into the Mop8 fibroblasts by transfection of GalT gene, Cer content was also significantly lowered (Figure 2). The salvage of intracellular Cer by glucosylation and/or galactosylation may prevent stress-related cell apoptosis. On the other hand, Beier and Görögh [15] hypothesized that the accumulation of GalCer upon the surface of numerous cancers is likely to be explained by a transcriptional GALC (lysosomal galactocerebrosidase) gene suppression. Furthermore, it was suggested that the increase of galactosylceramide per se is a pro- survival mechanism for breast cancer cells [16]. However, further analyses should be required to elucidate the linkage between the modulation of sphingolipid metabolism and apoptosis in normal and cancer cells. The potential of Cer-based therapeutics in the treatment of cancer, and the involvement of sphingolipids in cancer drug resistance have been excellently reviewed elsewhere $[17,18]$.

In MopGT we detected newly expressed glycolipids of glycerol type and analyzed the molecular species by MALDI-TOF MS. This glycosyl glycerolipid contained C16:0, C18:0 or C18:1 as an alkyl chain,
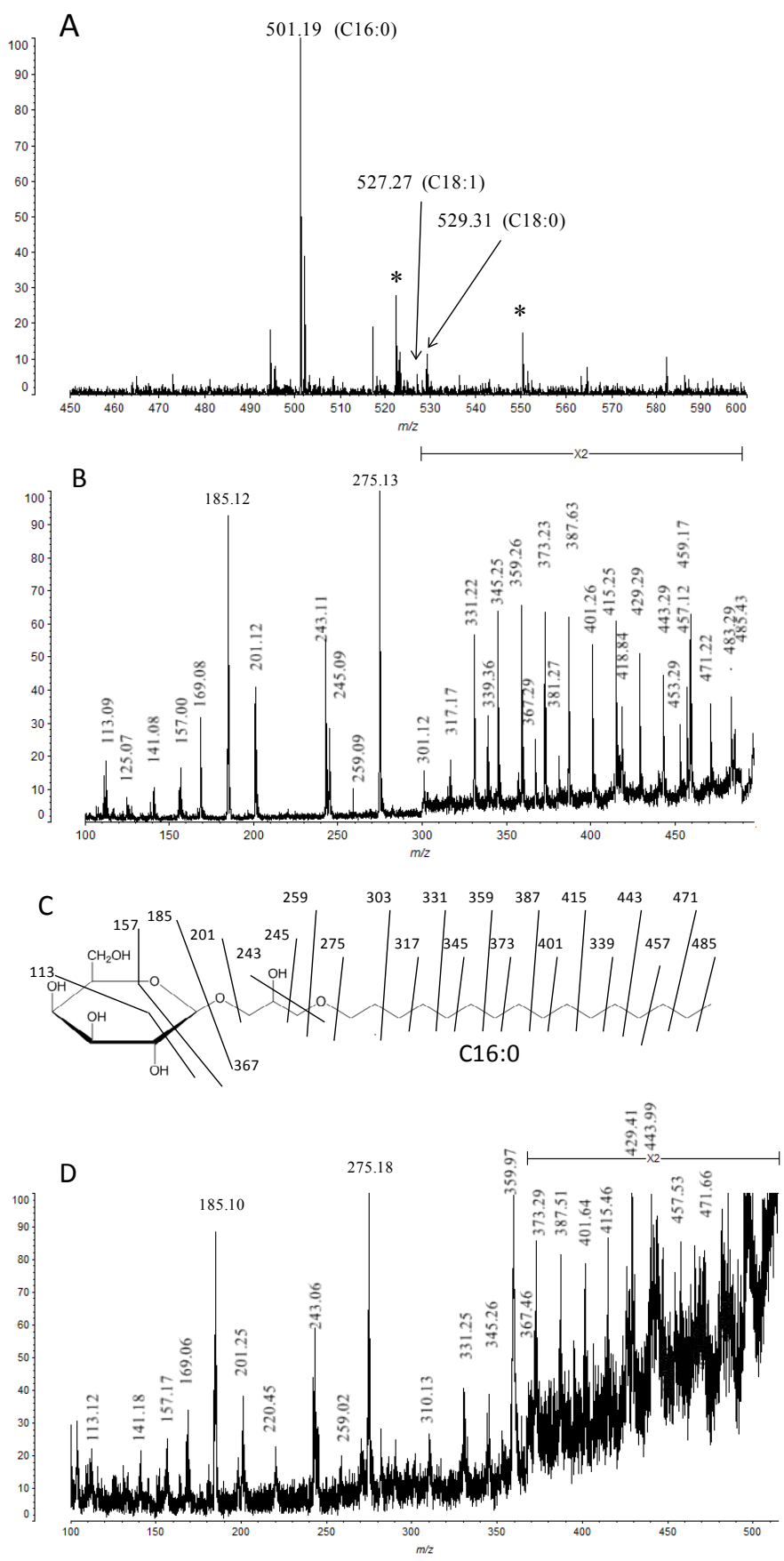

Figure 4. MALDI-TOF MS analysis of GTX. (A). Molecular ions $[\mathrm{M}+\mathrm{Na}]^{+}$of GTX *unidentified signal. (B) CID mass fragmentation spectrum of $\mathrm{m} / \mathrm{z} 501$ molecular ion in GTX (C16:0). (C) Assignment of mass fragments of GTX (m/z 501). (D) CID mass fragmentation spectrum of $\mathrm{m} / \mathrm{z} 529$ molecular ion in GTX (C18:0). 
A

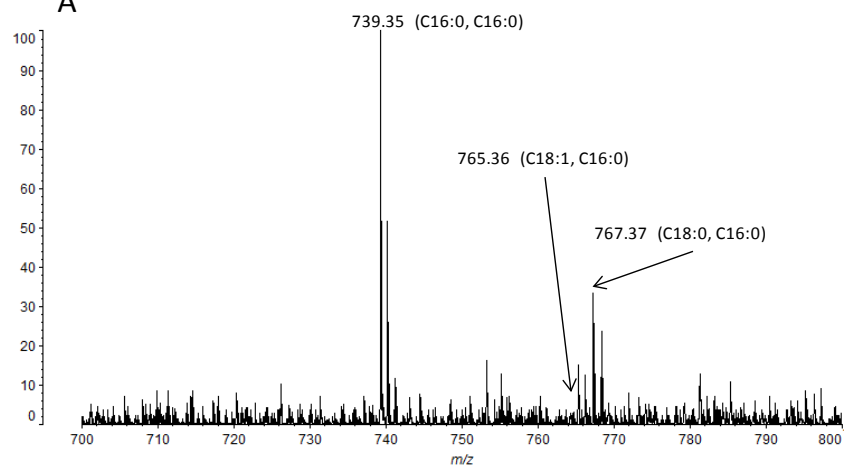

B

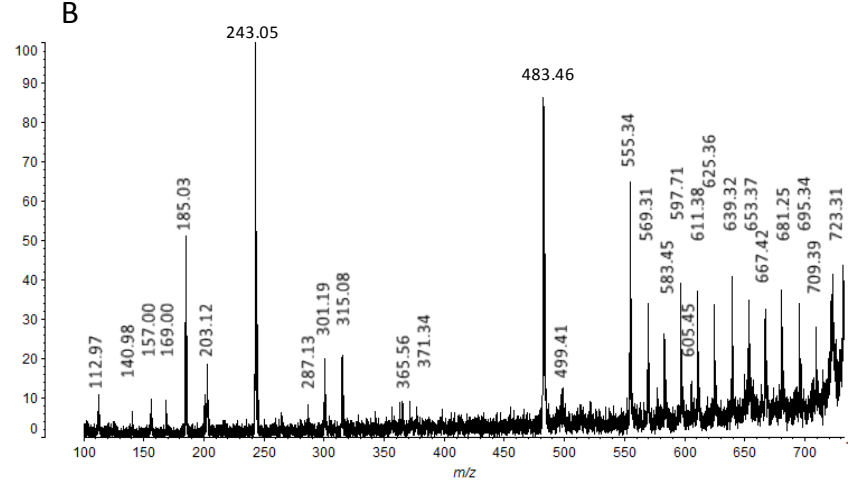

C

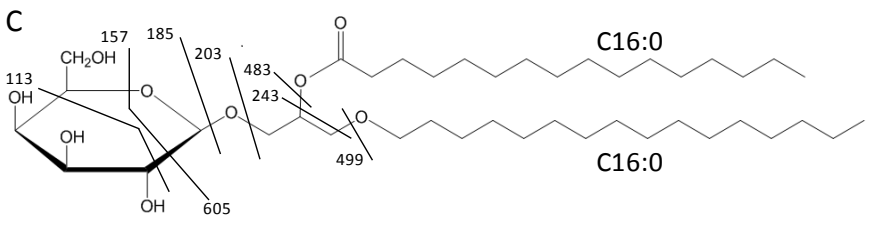

D
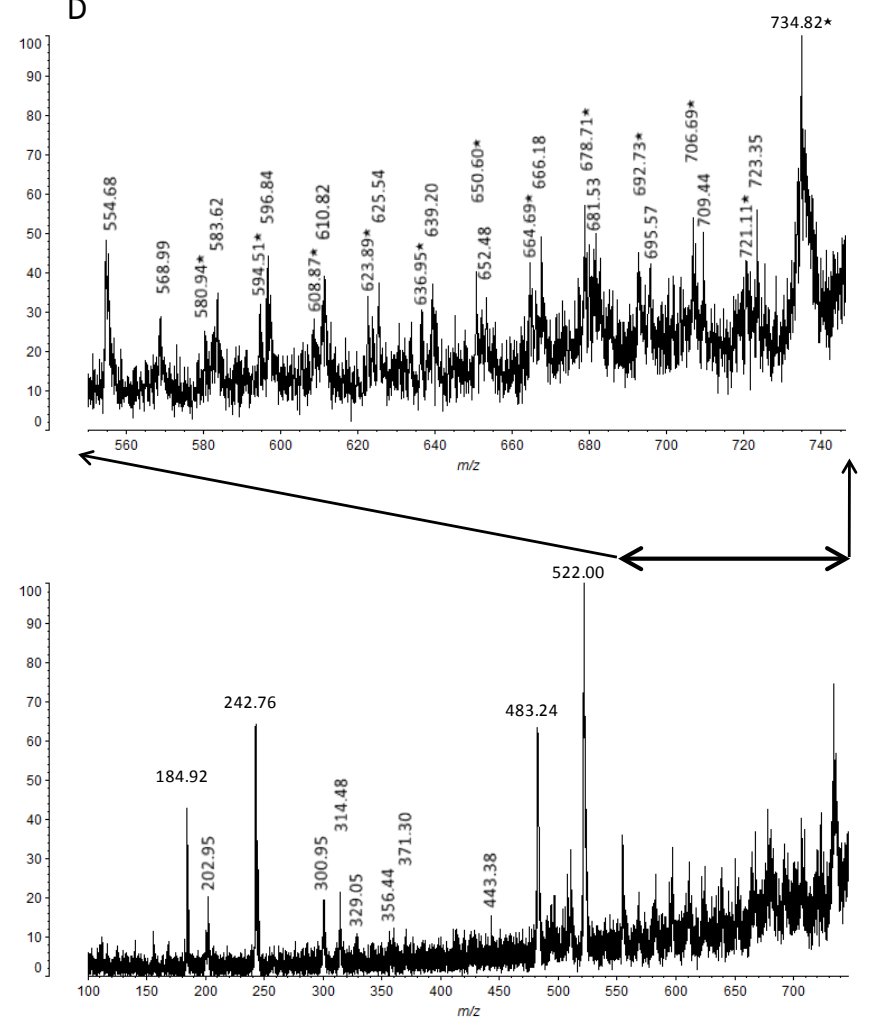

(185)

Figure 5. MALDI-TOF MS analysis of GTXorg. (A) MS spectrum of GTXorg. (B) CID mass fragmentation of m/z 739 in GTXorg (C16:0 alkyl, C16:0 acyl). (C) Assignment of mass fragments of GTXorg (m/z 739). (D) CID MS fragmentation spectrum of m/z 765-767 region of GTXorg (C18:1 alkyl, C16:0 acyl and C18:0 alkyl, C16:0 acyl). In upper expanded panel, mass numbers with closed star ( $\star$ ) are derived from GTXorg (C18:1 alkyl, C16:0 acyl). (E) Assignment of mass fragments of GlcCer (d18:1 sphingoid base, C16:0 acyl) from Mop8 cell $(\mathrm{m} / \mathrm{z} 723)[7]$.

while contained only C16:0 as an acyl chain. In our previous study, we demonstrated that predominant fatty acid of Cer and GlcCer in Mop8 cell was C16:0 [8]. Both alkylacyl glycerol [19] and Cer [20] are biosynthesized in endoplasmic reticulum and thus may be their acyl chains identical. Because $14 \mathrm{Da}$ (difference between a carbonyl group of acyl chain and a methylene group of alkyl chain) larger molecular ions were hardly observed in the MS spectra of GTXorg, the galactosyldiacyl glycerol type might be minor galactoglycerolipid of MopGT cell. In contrast, $\mathrm{CHO}$ cells transfected with the brain GalT gene expressed both of galactosyl-alkylacyl and galactosyl-diacyl glycerol [9]. It has been known that GalT galactosylates both hydroxy and non-hydroxy fatty acid-containing Cer and diglycerides, depending on their local availability [9]. Thus, it seems likely that GalT in MopGT could utilize mainly the alkylacyl glycerols mentioned above as the precursor substrates.

In our previous study [8], we have carried out MALDI-TOF MS analysis of GlcCer (d18:1, C16:0) from Mop8 cell with the almost same MS condition as the present study. When the CID fragmentation pattern of GTXorg (C16:0, C16:0) (Figure 5C) was compared with that of GlcCer (d18:1, C16:0) (Figure 5E), some identical or distinguishable ions were detected. Understandably, the identical ions at m/z 185 (B1) and 203 (C1) were generated from a Hex (Gal or Glc) of both GTXorg (C16:0, C16:0) and GlcCer (d18:1, C16:0). In contrast, the typical ions for GTXorg (C16:0, C16:0) at m/z 243, and 499 derived from a Hex and a part of glycerol, and a Hex and a part of glycerol with an acyl chain (C16:0), respectively, were observed. GlcCer (d18:1, C16:0) generated the typical ions at $\mathrm{m} / \mathrm{z} 244(\mathrm{E})$, and $304(\mathrm{a} 3-\mathrm{OH}+\mathrm{Na})$ derived from a Hex and a part of sphingoid base, and a Hex and a part of sphingoid base with an acyl chain (C16:0), respectively. The B1, C1, E and a 3 are ion designations of carbohydrate and their linkage portion to Cer [12,2123]. From a technical perspective, among the above four fragment ions, $\mathrm{m} / \mathrm{z} 499$ and 304 may be useful for the discrimination between GTXorg (C16:0, C16:0) and GlcCer (d18:1, C16:0). Tanaka et al. [12] reported that series of ions with a difference of $14 \mathrm{Da}\left(-\mathrm{CH}_{2}-\right)$ derived from acyl chain and sphingoid base were observed in MS/MS analyses of $[\mathrm{M}+\mathrm{Na}]^{+}$ ions from Cer and HexCer. These ion clusters have been reported to be generated by charge-remote fragmentation $[24,25]$. The corresponding series of ions were also detected in GTX and GTXorg (Figures 4B, 5B and 5D). Similarly to neutral glycosphingolipids besides Cer, MALDITOF MS with high-energy CID of neutral glycoglycerolipids would also be a useful approach to collect their structural information.

In animal tissues, the expression of glycoglycerolipids seems to be 
limited, and their localization might be only in the testis and nervous system. Galactosyl glycerolipid was associated mainly with microsomes, myelin and synaptic vesicles in rat brain. A transient increase in the concentration of the galactosyl glycerolipid in rat brain was observed at the time of active myelination, suggesting developmentally regulated expression of this molecule [19]. Galactosyl-alkylacyl glycerolipid was also detected from HT29 colon cancer cells [26]. The expression of galactosyl glycerolipid was greatly diminished when HT29 cells were induced to differentiate. This loss of galactosyl glycerolipid expression suggests that the glycerolipid may be expressed during certain stages of differentiation of colonocytes [26]. Similarly, there is the possibility that Mop 8 fibroblasts may express the galactosyl-alkylacyl glycerolipid at the time of malignant transformation, while the more detailed investigation should be necessary to address this issue. In addition, it is not clear at present whether the galactosyl-alkylacyl glycerol serves as a better marker for cancer diagnosis/prognosis than GalCer or not.

\section{References}

1. Hannun YA, Obeid LM (2008) Principles of bioactive lipid signalling: lessons from sphingolipids. Nat Rev Mol Cell Biol 9: 139-150. [Crossref]

2. Bartke N, Hannun YA (2009) Bioactive sphingolipids: metabolism and function. $J$ Lipid Res 50 Suppl: S91-96. [Crossref]

3. Wang T, Wei J, Wang N, Ma JL, Hui PP (2015) The glucosylceramide synthase inhibitor PDMP sensitizes pancreatic cancer cells to MEK/ERK inhibitor AZD-6244. Biochem Biophys Res Commun 456: 821-826. [Crossref]

4. Nikolova-Karakashian MN, Rozenova KA (2010) Ceramide in stress response. $A d v$ Exp Med Biol 688: 86-108. [Crossref]

5. Niimura Y, Nagai K (2008) Metabolic responses of sulfatide and related glycolipids in Madin-Darby canine kidney (MDCK) cells under osmotic stresses. Comp Biochem Physiol B Biochem Mol Biol 149: 161-167. [Crossref]

6. Niimura Y, Moue T, Takahashi N, Nagai K (2010) Medium osmolarity-dependent biosynthesis of renal cellular sulfoglycolipids is mediated by the MAPK signaling pathway. Biochim Biophys Acta 1801: 1155-1162. [Crossref]

7. Niimura Y, Moue T, Takahashi N, Nagai K (2010) Modification of sphingoglycolipids and sulfolipids in kidney cell lines under heat stress: Activation of monohexosylceramide synthesis as a ceramide scavenger. Glycobiology 20: 710-717. [Crossref]

8. Nagai K, Takahashi N, Moue T, Niimura Y (2011) Alteration of fatty acid molecular species in ceramide and glucosylceramide under heat stress and expression of sphingolipid-related genes. Adv Biol Chem 1: 35-48.

9. van der Bijl P, Strous GJ, Lopes-Cardozo M, Thomas-Oates J, et al. (1996) Synthesis of non-hydroxy-galactosylceramides and galactosyldiglycerides by hydroxy-ceramide galactosyltransferase. Biochem J 317 ( Pt 2): 589-597. [Crossref]

10. Muller WJ, Naujokas MA, Hassell JA (1984) Isolation of large T antigen-producing mouse cell lines capable of supporting replication of polyomavirus-plasmid recombinants. Mol Cell Biol 4: 2406-2412. [Crossref]
11. Schulte S, Stoffel W (1993) Ceramide UDPgalactosyltransferase from myelinating rat brain: purification, cloning, and expression. Proc Natl Acad Sci U S A 90: 10265-10269. [Crossref]

12. Tanaka K, Yamada M, Tamiya-Koizumi K, Kannagi R, Aoyama T, et al. (2011) Systematic analyses of free ceramide species and ceramide species comprising neutral glycosphingolipids by MALDI-TOF MS with high-energy CID. Glycoconj $J$ 28: 67-87. [Crossref]

13. Komori H, Ichikawa S, Hirabayashi Y, Ito M (1999) Regulation of intracellular ceramide content in B16 melanoma cells. Biological implications of ceramide glycosylation. $J$ Biol Chem 274: 8981-8987. [Crossref]

14. Uchida Y, Murata S, Schmuth M, Behne MJ, Lee JD, et al. (2002) Glucosylceramide synthesis and synthase expression protect against ceramide-induced stress. J Lipid Res 43: 1293-1302. [Crossref]

15. Beier UH, Görögh T (2005) Implications of galactocerebrosidase and galactosylcerebroside metabolism in cancer cells. Int J Cancer 115: 6-10. [Crossref]

16. Owczarek TB, Suchanski J, Pula B, Kmiecik AM, Chadalski M, et al. (2013) Galactosylceramide affects tumorigenic and metastatic properties of breast cancer cells as an anti-apoptotic molecule. PLoS One 8: e84191. [Crossref]

17. Morad SA, Cabot MC (2013) Ceramide-orchestrated signalling in cancer cells. Nat Rev Cancer 13: 51-65. [Crossref]

18. Giussani P, Tringali C, Riboni L, Viani P, Venerando B (2014) Sphingolipids: key regulators of apoptosis and pivotal players in cancer drug resistance. Int J Mol Sci 15: 4356-4392. [Crossref]

19. Ishizuka I, Yamakawa T (1985) Glycoglycerolipids. In: Wiegandt H, ed. Glycolipids Elsevier Science Publishers BV: pp.101-196.

20. Hirabayashi Y (2012) A world of sphingolipids and glycolipids in the brain--novel functions of simple lipids modified with glucose. Proc Jpn Acad Ser B Phys Biol Sci 88: 129-143. [Crossref]

21. Domon B, Costello CE (1988) A systematic nomenclature for carbohydrate fragmentations in FAB-MS/MS spectra of glycoconjugates. Glycoconj J 5: 397-409.

22. Costello CE, Vath JE (1990) Tandem mass spectrometry of glycolipids. Methods Enzymol 193: 738-768. [Crossref]

23. Matsuda J, Kido M, Tadano-Aritomi K, Ishizuka I, Tominaga K, et al. (2004) Mutation in saposin D domain of sphingolipid activator protein gene causes urinary system defects and cerebellar Purkinje cell degeneration with accumulation of hydroxy fatty acid-containing ceramide in mouse. Hum Mol Genet 13: 2709-2723. [Crossref]

24. Adams J, Gross ML (1989) Charge-remote fragmentations of closed-shell ions. A thermolytic analogy. J Am Chem Soc 111: 435-440.

25. Harvey DJ (2005) A new charge-associated mechanism to account for the production of fragment ions in the high-energy CID spectra of fatty acids. J Am Soc Mass Spectrom 16: 280-290. [Crossref]

26. Påhlsson P, Spitalnik SL, Spitalnik PF, Fantini J, Rakotonirainy O, et al. (2001) Characterization of galactosyl glycerolipids in the HT29 human colon carcinoma cell line. Arch Biochem Biophys 396: 187-198. [Crossref]

Copyright: (C2016 Nagai K. This is an open-access article distributed under the terms of the Creative Commons Attribution License, which permits unrestricted use, distribution, and reproduction in any medium, provided the original author and source are credited. 